\title{
Feasibility of 2D-conformal radiotherapy for pancreatic carcinoma
}

\author{
MILLY BUWENGE ${ }^{1}$, SAVINO CILLA $^{2}$, SILVIA CAMMELLI ${ }^{1}$, GABRIELLA MACCHIA ${ }^{3}$, ALESSANDRA ARCELLI ${ }^{1}$, \\ ELEONORA FARINA ${ }^{4}$, REZARTA FRAKULLI ${ }^{5}$, VALERIA PANNI ${ }^{1}$, TIGENEH WONDEMAGEGNHU ${ }^{6}$, \\ A. F. M. KAMAL UDDIN ${ }^{7}$, MOSTAFA A. SUMON ${ }^{7}$, FRANCESCO DEODATO ${ }^{3}$ and ALESSIO G. MORGANTI ${ }^{1}$ \\ ${ }^{1}$ Radiation Oncology Center, Department of Experimental, Diagnostic and Specialty Medicine-DIMES, University of Bologna, \\ S. Orsola-Malpighi Hospital, 40138 Bologna; ${ }^{2}$ Medical Physic Unit; ${ }^{3}$ Radiotherapy Unit, Fondazione di Ricerca e Cura \\ 'Giovanni Paolo II', Catholic University of Sacred Heart, 86100 Campobasso; ${ }^{4}$ Department of Radiation Oncology, \\ CRO-IRCCS, National Cancer Institute, 33081 Aviano; ${ }^{5}$ Radiation Oncology Unit, Bellaria Hospital, 40139 Bologna, Italy; \\ ${ }^{6}$ Department of Radiation Oncology, Black Lion Hospital, Addis Ababa 9086, Ethiopia; \\ ${ }^{7}$ Radiation Oncology Department, United Hospital Limited, Gulshan, Dhaka 1212, Bangladesh
}

Received May 7, 2018; Accepted July 25, 2018

DOI: $10.3892 /$ ol.2018.9389

\begin{abstract}
The purpose of the present study was to propose an optimized 2D technique (2D-conformal) for radiotherapy (RT) of pancreatic cancer $(\mathrm{CaP})$. This technique is based on double simulation which resolves the problems of radiographic image distortion. Five patients with locally advanced $\mathrm{CaP}$ were identified and enrolled. Treatment planning was simulated in 3 different ways: Two dimensional-standard (2D-SRT), 2D-conformal (2D-CRT), and three dimensional-conformal (3D-CRT) techniques for $10 \mathrm{MV}$ LINAC. Simulation for a cobalt machine was also performed using only the $2 \mathrm{D}$ techniques. 2D-SRT technique was planned with fields definition based on anatomical landmarks (bone and duodenum). 3D-CRT was planned with standard virtual simulation technique, and 3D dose evaluation and optimization. 2D-CRT technique was based on manual information transfer from a diagnostic CT-scan to simulation radiograms. To eliminate the X-ray image distortion, a double simulation was employed and the profile of the GTV was delineated on radiographs bearing the simulator isocenter into the target center. Concerning target irradiation of either LINAC (10 MV) or cobalt source, the PTV constraints (ICRU 62) were met in all patients $\left(D_{\min }>95 \%, D_{\max }<107 \%\right)$ with all techniques (2D-SRT, 3D-CRT, 2D-CRT). For organs at risk irradiation, in terms of $\mathrm{D}_{\max }$ to both duodenum and spinal cord, similar results were recorded with all techniques using the LINAC (10 MV).
\end{abstract}

Correspondence to: Dr Milly Buwenge, Radiation Oncology Center, Department of Experimental, Diagnostic and Specialty Medicine-DIMES, University of Bologna, S. Orsola-Malpighi Hospital, 9 Via Giuseppe Massarenti, 40138 Bologna, Italy E-mail: mbuwenge@gmail.com

Key words: pancreatic neoplasms, conformal radiotherapy, 2D, simulation, developing countries
Liver and kidneys $\mathrm{D}_{\text {mean }}$ gradually improved from 2D-SRT to 2D-CRT and 3D-CRT. The 2D-CRT compared to 2D-SRT technique, halved the average dose to the liver and reduced to about $1 / 3$ the average dose to the kidneys. With the cobalt source, using the $2 \mathrm{D}-\mathrm{CRT}$ produced a reduction of $\mathrm{D}_{\text {mean }}$ to the kidneys (median from 30.7 to $16.9 \%$ ) and liver (median from 33.4 to $22.3 \%$ ) compared to 2D-SRT. This analysis showed better planning results in $\mathrm{RT}$ treatment of $\mathrm{CaP}$ while using a 2D-CRT compared to 2D-SRT technique and therefore presents an example for optimized 2D RT use.

\section{Introduction}

Three-dimensional conformal radiotherapy (3D-CRT) has gradually developed and spread since the 90s. Currently this technique is the standard radiotherapy (RT) treatment in many centers worldwide. It is based on virtual simulation and requires three-dimensional treatment planning systems (3D-TPS) and linear accelerators equipped with multileaf collimators (MCLs) (1).

In several RT centers, especially in developing countries, 3D-CRT is not available and 2D-RT is still the only used technique (2). In 2014 an estimation of over 10,846 high-energy RT machines operating showed that 2,386 were still represented by cobalt units (3).

$\mathrm{RT}$ of pancreatic cancer $(\mathrm{CaP})$ has been tested in recent decades in different settings (neoadjuvant, adjuvant, and palliative treatment) and nowadays is considered as a therapeutic option for $\mathrm{CaP}$ (4). However, $\mathrm{RT}$ in $\mathrm{CaP}$ is currently less used in developing countries due to technological limitations. In fact, in these centers RT fields are still planned with conventional simulators or a C-arm X-ray unit and the treatments are frequently delivered with cobalt machines. A precise targeting of $\mathrm{CaP}$ is difficult because these tumors are not visible on plain radiographs. In addition, 2D-RT is not able to produce an optimal and homogeneous dose distributions. This issue is particularly relevant in $\mathrm{CaP}$, considering several organs at risk 
(OARs) such as spinal cord, duodenum, liver and kidneys that surround the pancreas.

Currently with the diffuse use of computerized tomography (CT) images now available in almost all centers and the conventional X-ray images produced by a simulator equipment. Therefore, theoretically we could hypothesis conformation of treatment fields by combination of extrapolated radiological information from the available images.

Based on these premises, the objective of this analysis was to propose an optimized planning technique for $\mathrm{CaP}$. This technique is based on double simulation which resolves the problems of radiographic image distortion.

\section{Materials and methods}

Patients. In our center, 5 patients ( 2 female, 3 male) with locally advanced pancreatic head cancer undergoing RT treatment, aged 46 to75 years and with median body mass index of 23 (range: 21-29) were identified. Patients written informed consent for the use of their data and CT images to perform this analysis was sought prior. The Institutional Ethical Committee Board of High Technology Center for Research and Education (Campobasso, Italy) approved the study. Treatment planning was performed with 3 different methods: Standard two-dimensional (2D-SRT), three-dimensional-conformal (3D-CRT) and 2D-conformal (2D-CRT). In Table I, the characteristics of the 3 planning techniques are briefly summarized.

$2 D$-SRT. Based on our previous analysis (5), a box-technique based on standard fields was tested. In short, the treatment was planned as follows: i) Standard fields were placed in reference to anatomical structures visible on X-ray images (vertebrae and the duodenum. The latter was opacified at the time of simulation with oral contrast medium; ii) fields sizes were adapted according to the beam energy as shown in Table II (Fig. 1A and B).

$3 D$-CRT. Irradiation treatment plans were generated according to the standard processes of CT-simulation, target definition, and optimization of 3D dose distribution by using Dose Volume Histograms (DVHs) for Planning Target Volume (PTV) and Organs at Risk (OARs). Dose prescription was based on ICRU 62 indications (6).

$2 D$-CRT. With correct patients' alignment in supine position, conventional simulation was performed. For anterior-posterior (AP) radiographs, the centering point was on the posterior end of the L1 spinous process [defined as point A] (Fig. 1C). Lateral view (LL) radiographs had their center at the same anatomical landmark (Fig. 1D).

CT scans with the patient in the same position for treatment reproducibility were performed (Table I), extending from T9 to L5 with an interval between scans of $5 \mathrm{~mm}$. CT images were printed with a scale indicator display. The tumor had to be identified on all scans where it was visible. The scan displaying the center (in cranio-caudal direction) of the tumor was identified. The geometric center of the tumor [defined as the center of the rectangle circumscribing the visible tumor mass] (Fig. 2A) was indicated on this scan. This point was defined as point $\mathrm{B}$.
Then, the distance in 3 dimensions $(\mathrm{x}, \mathrm{y}, \mathrm{z})$ between point $\mathrm{A}$ and point $B$ was calculated: i) The distance of point $B$ from the center of the lumbar spine was measured, which corresponds to the lateral distance from point $\mathrm{B}$ to point $\mathrm{A}$, if the patient is correctly aligned (distance x, Fig. 2B); ii) the cranio-caudal distance was calculated as the distance between the level of the scan in which point $\mathrm{A}$ and $\mathrm{B}$ were visible (distance y); iii) the antero-posterior distance was defined by measuring the distance between point $\mathrm{A}$ and $\mathrm{B}$ from the $\mathrm{CT}$ bed and then calculating their relative difference (distance z, Fig. 2C and D);

Another simulation was then performed. Using the distances between point $\mathrm{A}$ and point $\mathrm{B}$, the simulator table/bed with the patient was moved to align point $\mathrm{B}$ (center of the target) with the simulator isocenter. Two new X-rays centered at point $\mathrm{B}$, one in the anterior-posterior projection and the other in lateral projection, were taken (Fig. 3A and B).

In consideration of the magnification factor, the Gross Tumor Volume (GTV) profiles at different scan levels were manually drawn (Fig. 3A and B). This profile defined GTV/Clinical Target Volume (CTV). Furthermore, PTV margins definition (14 mm cranial caudal direction and $11 \mathrm{~mm}$ in the radial direction, Fig. 3A and B) were added to the CTV. Another, margin of $10 \mathrm{~mm}$ to account for any inaccuracies in the profiles transfer from the $\mathrm{CT}$ images to the simulation radiographs was added to the PTV (Fig. 3A and B). The irradiation fields were obtained by adding an extra margin of $10 \mathrm{~mm}$ in cranio-caudal direction and $5 \mathrm{~mm}$ in the radial direction. Finally, a 2D dose distribution optimization was realized at the isocenter level only.

Comparison. Using a 3D TPS (Masterplan, Nucletron BV, Veenendaal, The Netherlands), 3D dose distributions and DVHs achieved with the 3 different treatment techniques were calculated using $10 \mathrm{MV}$ photons beams. For 2D techniques, calculation of the dose distribution by a cobalt source was also performed. Finally, compliance with the dose-volume constraints (QUANTEC) obtained with the 3 different techniques were evaluated (7). This evaluation was performed by calculating a set of parameters for the main OARs and assuming two different PTV dose prescriptions (30 Gy in $3 \mathrm{~Gy} /$ fraction and $50 \mathrm{~Gy}$ in $2 \mathrm{~Gy} /$ fraction).

\section{Results}

Target irradiation. Using the $10 \mathrm{MV}$ beam, the ICRU 62 indications were achieved in all patients $\left(\mathrm{D}_{\min }>95 \%, \mathrm{D}_{\max }<107 \%\right)$ with all techniques (SRT-2D, 3D-CRT, CRT-2D) (Table III).

Using the cobalt source, both 2D techniques achieved PTV $\mathrm{D}_{\min }<95 \%$ and PTV $\mathrm{D}_{\max }<107 \%$ in all patients. However, a dose $>95 \%$ of the prescribed was administered to $>95 \%$ of the PTV $\left(\mathrm{V}_{95 \%}>95 \%\right)$ in all patients (Table III).

OAR irradiation. Using the $10 \mathrm{MV}$ beams, the duodenum and spinal cord $\mathrm{D}_{\max }$ were substantially similar using the 3 treatment techniques. In terms of liver and kidneys $\mathrm{D}_{\text {mean }}$, there was a gradual improvement from 2D-SRT, 2D-CRT, and 3D-CRT technique. Furthermore, 2D-CRT, compared with 2D-SRT, halved liver $\mathrm{D}_{\text {mean }}$ and reduced to approximately $1 / 3$ the kidney $\mathrm{D}_{\text {mean }}$ (Table III).

Using the cobalt 60 source beams, similar results in terms of spinal cord and duodenum $\mathrm{D}_{\max }$ with both $2 \mathrm{D}$ techniques 
Table I. Fields definition for standard 2D radiotherapy.

\begin{tabular}{lllr}
\hline Fields & Margin & \multicolumn{1}{c}{ Reference points and directions } & Co60 \\
\hline Anterior- & Cranial & From point A (middle of T11 vertebra): caudally & 0 \\
Posterior & Caudal & From point B (bottom of the duodenal wall): caudally & 5 \\
& Right & From point C (most external point of the duodenum): laterally & 10 \\
& Left & From point D (left margin of L1 vertebra): laterally & 10 \\
& & Same as anterior-posterior & 15 \\
Lateral & Cranial & Same as anterior-posterior & 13 \\
& Caudal & Same as anterior-posterior & 0 \\
& Anterior & From point E (anterior surface of L1 vertebra): anteriorly & 15 \\
& Posterior & From point E (anterior surface of L1 vertebra): posteriorly & 95 \\
& & & 20 \\
\hline
\end{tabular}

Reported measurements represent minimal individual field margins needed to respect the PTV constraint Dmin $>90 \%$. Measurements are expressed in millimetres. ${ }^{10} \mathrm{PTV}$, planning target volume.

Table II. Planning characteristics.

\begin{tabular}{|c|c|c|c|}
\hline Characteristics & 2D-SRT & 2D-CRT & 3D-CRT \\
\hline $\begin{array}{l}\text { Standard } \\
\text { simulation }\end{array}$ & $\begin{array}{l}\text { With fields definition } \\
\text { based on bony landmarks } \\
\text { and duodenum }\end{array}$ & $\begin{array}{l}\text { With fields definition based on } \\
\text { manual reconstruction of the } \\
\text { target shape, dimension and position }\end{array}$ & Not performed \\
\hline CT scan & Not performed & T9-15; 5 mm scan interval & $\begin{array}{l}\text { CT-simulation; T9-15; } 5 \text { mm } \\
\text { scan interval }\end{array}$ \\
\hline Target definition & Not defined & $\begin{array}{l}\mathrm{GTV}=\text { tumor; } \mathrm{CTV}=\mathrm{GTV} \\
\mathrm{PTV}=\mathrm{CTV}+11 \mathrm{~mm} \text { radially } \\
\text { and } 14 \text { in cranio-caudal direction; } \\
\text { further margin of } 1 \mathrm{~cm} \text { added for } \\
\text { potential 'transfer errors' }\end{array}$ & $\begin{array}{l}\mathrm{GTV}=\text { tumor; } \mathrm{CTV}=\mathrm{GTV} \\
\mathrm{PTV}=\mathrm{CTV}+11 \mathrm{~mm} \text { radially and } \\
14 \text { in cranio-caudal direction }\end{array}$ \\
\hline Fields margins & $\begin{array}{l}\text { Based on anatomical } \\
\text { landmarks }\end{array}$ & $\begin{array}{l}\text { Around the PTV: } 2 \mathrm{~cm} \\
\left(\mathrm{Co}_{60}\right), 1.5 \mathrm{~cm}(10 \mathrm{MV})\end{array}$ & $\begin{array}{l}\text { Adapted based on dose distribution } \\
\text { using 3D TPS }\end{array}$ \\
\hline Beam weight & $\begin{array}{l}\text { Adapted based on dose } \\
\text { distribution using 2D } \\
\text { TPS (only at isocenter) }\end{array}$ & $\begin{array}{l}\text { Adapted based on dose distribution } \\
\text { using 2D TPS (only at isocenter) }\end{array}$ & $\begin{array}{l}\text { Adapted based on dose distribution } \\
\text { using 3D TPS }\end{array}$ \\
\hline
\end{tabular}

2D-SRT, standard 2D technique; 2D-CRT, optimized 2D conformal technique; 3D-CRT, 3D conformal technique; CT, computer tomography; GTV, gross tumor volume; CTV, Clinical tumor volume; PTV, planning target volume; TPS, treatment planning system; $\mathrm{Co}_{60}$, cobalt 60 .

were recorded. A marked dose reduction to the kidneys $\mathrm{D}_{\text {mean }}$ (from 30.7 to $16.9 \%$ ) and liver (from 33.4 to $22.3 \%$ ) were observed with 2D-CRT.

Dose-volume constraints. Tables IV and V show the results in terms of irradiation of the OAR, at the two different prescribed dose levels of 30 and $50 \mathrm{~Gy}$, respectively. The duodenum, spinal cord and liver dose-volume constraints were always met, for any prescribed dose and with all used techniques. Regarding the kidney $\mathrm{D}_{\text {mean }}$, only $10 \mathrm{MV}$ photons with $30 \mathrm{~Gy}$ dose met the constraint in all patients, irrespective of the technique. At the same dose level, and by using the cobalt 60 source, only 2D-CRT respected the constraint $\mathrm{D}_{\text {mean }}<15 \mathrm{~Gy}$ in all patients, while exceeded this limit in one patient using 2D-SRT. Using the 50 Gy dose with $10 \mathrm{MV}$ energy, 2D-CRT and 3D-CRT complied in all patients with the kidneys $\mathrm{D}_{\text {mean }}$ constraint. At the same dose level, with a cobalt source, neither of the two 2D techniques achieved a $\mathrm{D}_{\text {mean }}<15 \mathrm{~Gy}$ in all patients.

\section{Discussion}

In the past, different methods for 3D information transfer from CT scans to simulator X-rays were proposed (8-10). The interest in these solutions disappeared due to the spread of 3D-CRT based on CT-simulation, 3D-TPS and MCLs. However, 2D technology is still the only technique available in most developing countries. The lack of 3D-CRT in some centers, limits the use of RT especially in the treatment of malignancies requiring precision in target definition and OARs sparing. 

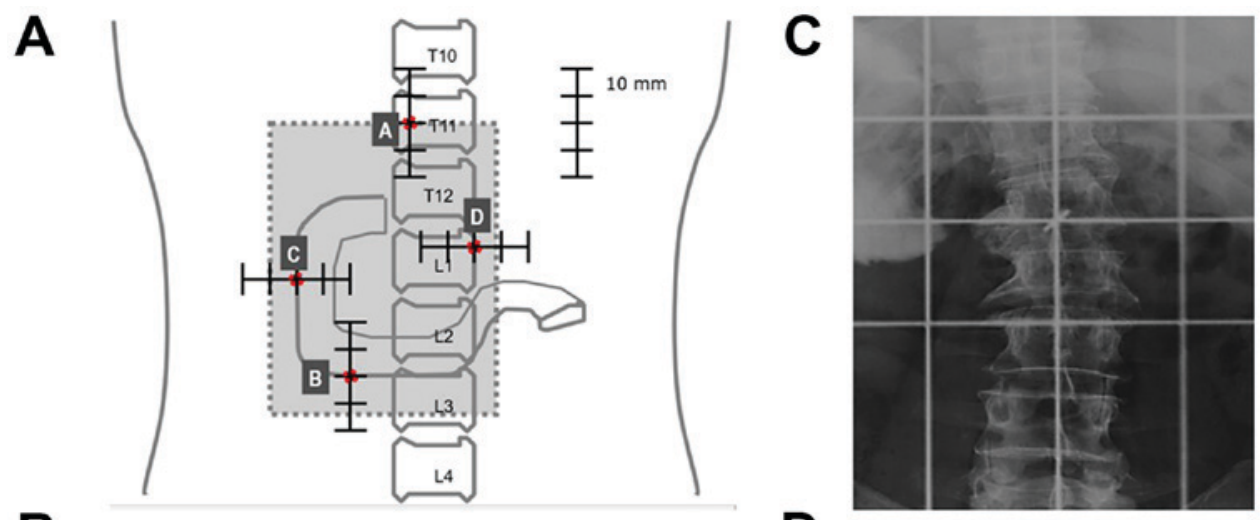

B
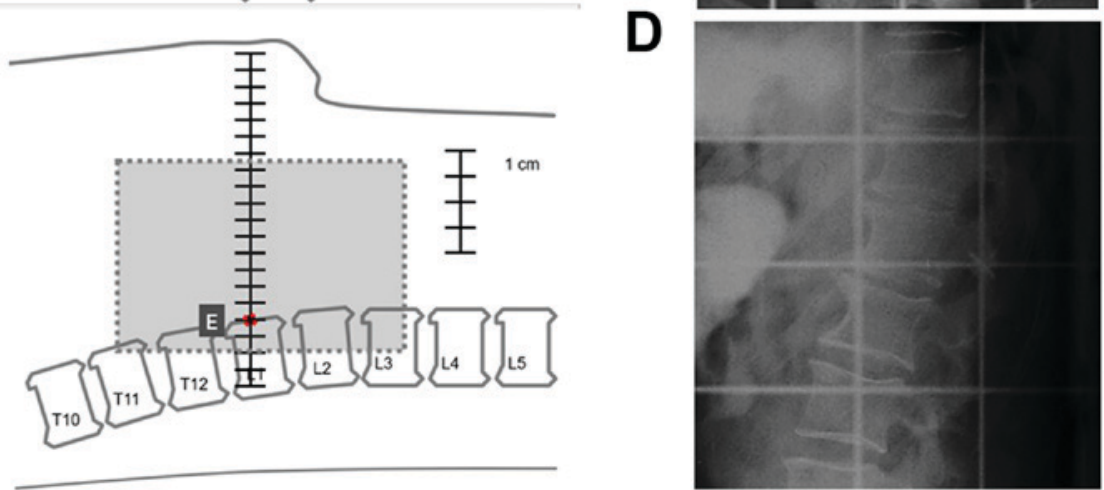

Figure 1. 2D standard technique fields and 1st simulation of 2D conformal planning. (A) Antero-posterior irradiation fields used in 2D-standard technique [cobalt 60 source]; (B) latero-lateral irradiation fields used in 2D-standard technique [cobalt 60 source]; (C) 2D-conformal techniques: The first anteroposterior simulation radiograph centered on L1 spinous process [point A]; (D) 2D-conformal techniques: The first latero-lateral simulation radiograph centered on L1 spinous process [point A].
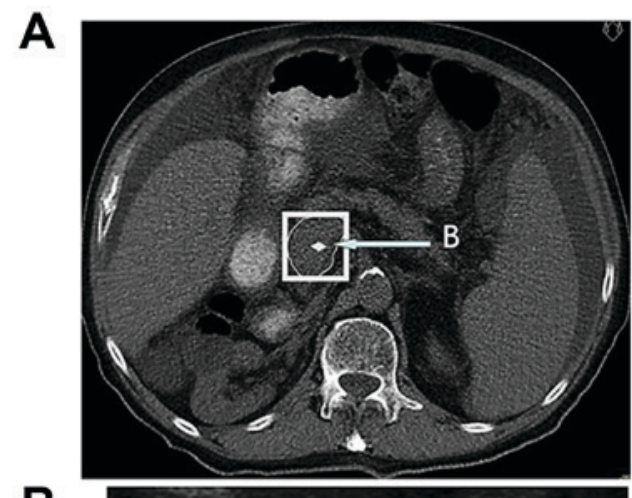

B

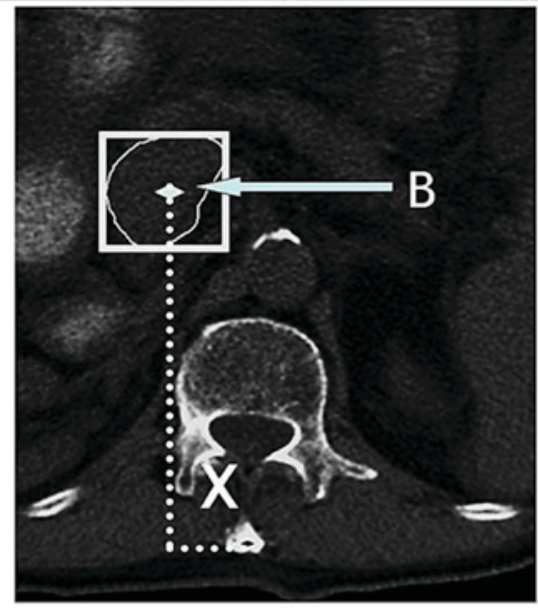

C

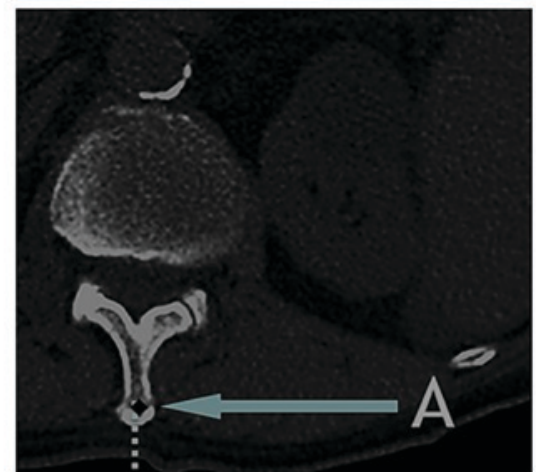

D

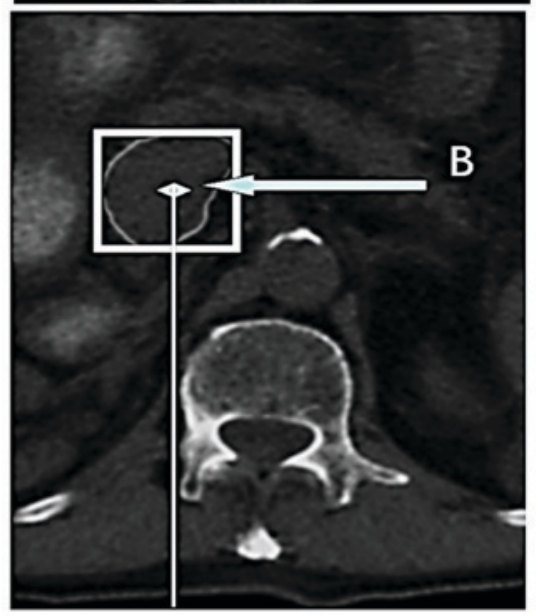

Figure 2. CT reference points and measurements for 2D conformal planning. (A) CT image at the tumor center (in cranio-caudal direction). The point B is defined as the geometric center of the rectangle circumscribing the tumor; (B) measurement of the lateral distance between point B and the center of the lumbar spine [used as the lateral distance between point A and point B]; (C) measurement of the distance of point A from the couch; (D) measurement of the distance of point B from the couch. The difference between the two distances was used to define the distance in anterior-posterior direction between point A and point B. 
Table III. Planning results.

A, Cobalt 60 source

\begin{tabular}{|c|c|c|c|c|}
\hline Organs at risk & Parameter, median (range) & 2D-SRT & 2D-CRT & 3D-CRT \\
\hline \multirow[t]{3}{*}{ PTV } & $\mathrm{V}_{95 \%}$ & $98.9(95.3-100.0)$ & $99.6(95.1-100.0)$ & $\mathrm{NE}$ \\
\hline & $\mathrm{V}_{107 \%}$ & $0.0(0.0-0.0)$ & $0.0(0.0-0.0)$ & $\mathrm{NE}$ \\
\hline & $\mathrm{D}_{\text {mean }}$ & $99.5(99.1-100.2)$ & $99.9(98.4-100.0)$ & NE \\
\hline Duodenum & $\mathrm{D}_{\max }$ & $102.0(101.2-103.5)$ & $102.3(64.8-102.4)$ & NE \\
\hline Liver & $\mathrm{D}_{\text {mean }}$ & $33.4(7.1-49.3)$ & $22.3(12.1-27.6)$ & $\mathrm{NE}$ \\
\hline Spinal cord & $\mathrm{D}_{\max }$ & $77.7(74.8-96.7)$ & $83.9(81.3-90.4)$ & $\mathrm{NE}$ \\
\hline Kidney & $\mathrm{D}_{\text {mean }}$ & $30.7(23.3-52.5)$ & $16.9(9.4-43.9)$ & $\mathrm{NE}$ \\
\hline
\end{tabular}

\section{B, LINAC $10 \mathrm{MV}$}

\begin{tabular}{lcccc}
\hline Organs at risk & Parameter, median (range) & 2D-SRT & 2D-CRT & 3D-CRT \\
\hline PTV & $\mathrm{V}_{95 \%}$ & $100(100-100)$ & $100(100-100)$ & $100(100-100)$ \\
& $\mathrm{V}_{107 \%}$ & $0(0-0)$ & $0(0-0)$ & $0(0-0)$ \\
& $\mathrm{D}_{\text {mean }}$ & $100.8(100.3-101.3)$ & $100.4(99.8-100.9)$ & $100.0(99.4-100.2)$ \\
Duodenum & $\mathrm{D}_{\text {max }}$ & $103.0(101.6-104.2)$ & $101.9(100.5-103.7)$ & $101.2(100.3-102.6)$ \\
Liver & $\mathrm{D}_{\text {mean }}$ & $30.8(9.7-45.7)$ & $17.3(3.8-21.9)$ & $11.0(2.1-16.6)$ \\
Spinal cord & $\mathrm{D}_{\text {max }}$ & $72.8(67.6-98.1)$ & $71.5(67.8-72.5)$ & $71.1(66.5-72.3)$ \\
Kidney & $\mathrm{D}_{\text {mean }}$ & $35.6(20.7-47.6)$ & $10.6(4.8-21.7)$ & $5.8(2.9-16.2)$ \\
\hline
\end{tabular}

Values are expressed as percentages. 2D-SRT, standard 2D technique; 2D-CRT, optimized 2D conformal technique; 3D-CRT, 3D conformal technique; NE, not evaluated; PTV, planning target volume.
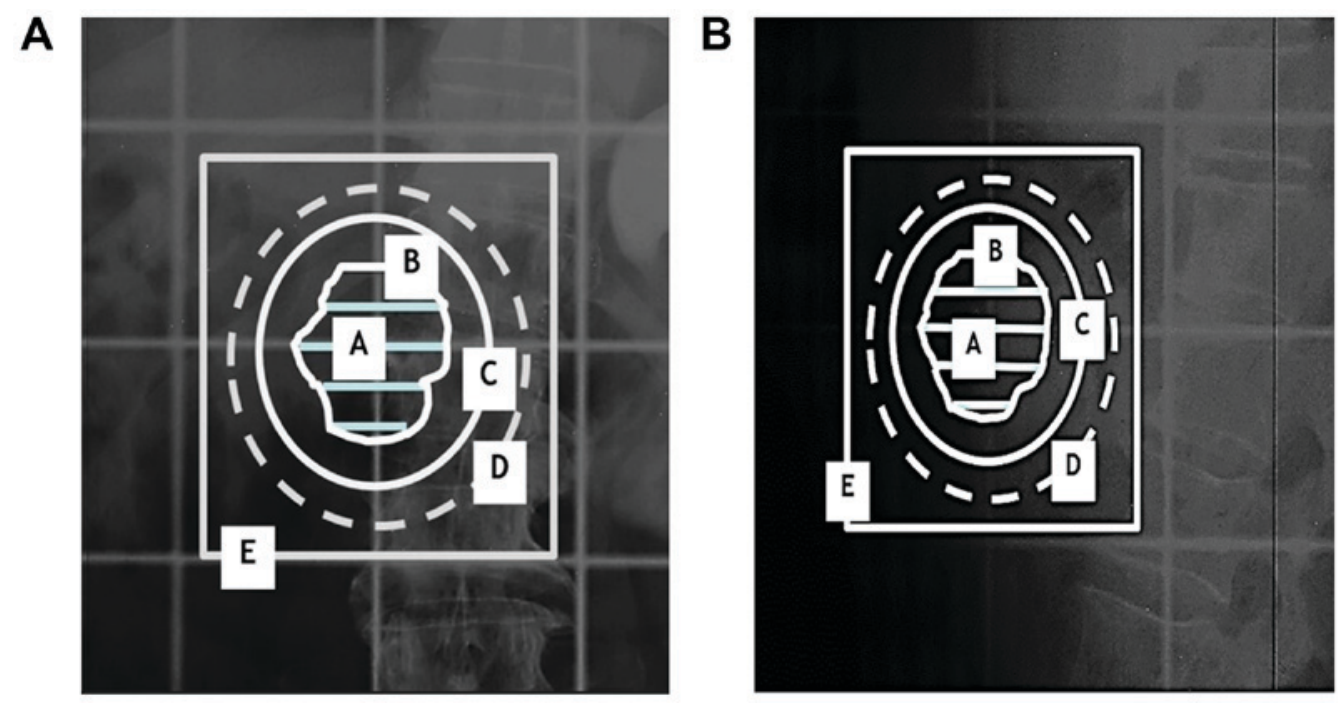

Figure 3. Secimulation of 2D conformal planning. (A) Second simulation: Manual drawing in anterior-posterior of the profile of the GTV (identified as the CTV) and of the PTV, obtained by adding to CTV a margin of $14 \mathrm{~mm}$ in cranio-caudal direction and $11 \mathrm{~mm}$ in the radial direction. To the PTV was added an additional $1 \mathrm{~cm}$ margin to account for the transfer error; (B) second simulation: Manual drawing in lateral-lateral direction of the profile of the GTV (identified as the CTV) and of the PTV, obtained by adding to CTV a margin of $14 \mathrm{~mm}$ in cranio-caudal direction and $11 \mathrm{~mm}$ in the radial direction. To the PTV was added an additional $1 \mathrm{~cm}$ margin to account for the transfer error.

In a previous study, we observed that with 2D-SRT, it is possible to meet the current standard dose-volume constraints (7) only by using lower total doses (30-36 Gy) (11). In a subsequent study, we defined the optimal fields size for involved-field irradiation of CaP with 2D-SRT technique (5).
In our current study, again CaP was used as a model for an optimized irradiation 2D technique (2D-CRT) feasibility for consistency. The main problem in the transfer of images from a CT slice to a simulator radiograph is the radiological image distortion depending on the beam projection. In the technique 
Table IV. Dosimetrical results for Organs at Risk with total prescribed dose of 30 Gy.

A, Cobalt 60 source

\begin{tabular}{lcccc}
\hline Organ & Parameter, constraint & Standard 2D & Optimized 2D & Conformal 3D \\
\hline Duodenum & $\mathrm{D}_{\max }<55$ & $30.6(30.4-31.0)$ & $30.7(19.4-30.7)$ & $\mathrm{NE}$ \\
Liver & $\mathrm{D}_{\operatorname{mea}}<30$ & $10.2(2.1-14.8)$ & $6.7(3.6-8.3)$ & $\mathrm{NE}$ \\
Spinal cord & $\mathrm{D}_{\max }<50$ & $23.3(22.4-29.0)$ & $25.2(24.4-27.1)$ & $\mathrm{NE}$ \\
Kidney & $\mathrm{D}_{\text {mean }}<15$ & $9.2(7.0-15.7)$ & $5.1(2.8-13.2)$ & $\mathrm{NE}$ \\
\hline
\end{tabular}

B, LINAC $10 \mathrm{MV}$

\begin{tabular}{lcccc}
\hline Organ & Parameter, constraint & Standard 2D & Optimized 2D & Conformal 3D \\
\hline Duodenum & $\mathrm{D}_{\max }<55$ & $30.9(30.5-31.3)$ & $30.6(30.1-31.1)$ & $30.4(30.1-30.8)$ \\
Liver & $\mathrm{D}_{\text {mean }}<30$ & $9.2(2.9-13.7)$ & $5.2(1.1-6.6)$ & $3.3(0.6-4.9)$ \\
Spinal cord & $\mathrm{D}_{\max }<50$ & $21.8(20.3-29.4)$ & $21.4(20.3-21.7)$ & $21.3(19.9-21.7)$ \\
Kidney & $\mathrm{D}_{\text {mean }}<15$ & $10.7(6.2-14.3)$ & $3.2(1.4-6.5)$ & $1.7(0.9-4.9)$ \\
\hline
\end{tabular}

Median values (range) are expressed in Gray. 2D-SRT, standard 2D technique; 2D-CRT, optimized 2D conformal technique; 3D-CRT, $3 \mathrm{D}$ conformal technique; NE, not evaluated.

Table V. Dosimetrical results for Organs at Risk with total prescribed dose of $50 \mathrm{~Gy}$.

\begin{tabular}{lcccc} 
A, Cobalt 60 source & & & & \\
\hline Organ & Parameter, constraint & 2D-SRT & 2D-CRT & 3D-CRT \\
\hline Duodenum & $\mathrm{D}_{\max }<55$ & $51.0(50.6-51.7)$ & $51.1(32.4-51.2)$ & $\mathrm{NE}$ \\
Liver & $\mathrm{D}_{\text {mean }}<30$ & $16.7(3.5-24.6)$ & $11.1(6.0-13.8)$ & $\mathrm{NE}$ \\
Spinal cord & $\mathrm{D}_{\text {max }}<50$ & $38.8(37.4-48.3)$ & $41.9(40.6-45.2)$ & $\mathrm{NE}$ \\
Kidney & $\mathrm{D}_{\text {mean }}<15$ & $15.3(11.6-26.2)$ & $8.4(4.7-21.9)$ & $\mathrm{NE}$
\end{tabular}

\section{B, LINAC $10 \mathrm{MV}$}

\begin{tabular}{lcccc}
\hline Organ & Parameter, constraint & 2D-SRT & 2D-CRT & 3D-CRT \\
\hline Duodenum & $\mathrm{D}_{\max }<55$ & $51.5(50.8-52.1)$ & $50.9(50.2-51.8)$ & $50.6(50.1-51.3)$ \\
Liver & $\mathrm{D}_{\text {mean }}<30$ & $15.4(4.8-22.8)$ & $8.6(1.9-10.9)$ & $5.5(1.0-8.3)$ \\
Spinal cord & $\mathrm{D}_{\max }<50$ & $36.4(33.8-49.0)$ & $35.7(33.9-36.2)$ & $35.5(33.2-36.1)$ \\
Kidney & $\mathrm{D}_{\text {mean }}<15$ & $17.8(10.3-23.8)$ & $5.3(2.4-10.8)$ & $2.9(1.4-8.1)$ \\
\hline
\end{tabular}

Median values (range) are expressed in Gray. 2D-SRT, standard 2D technique; 2D-CRT, optimized 2D conformal technique; 3D-CRT, 3D conformal technique.

proposed in this study, this problem is solved by 'double' simulation. The GTV is drawn on a second simulated image where the machine isocentre is placed directly at the center of the target. This solution eliminates the problems of image distortion.

When we conducted a comparison between 2D-SRT and the two optimized CT information-based 3D-CRT and 2D-CRT techniques. The analysis showed that the latter technique can substantially improve the dosimetric results compared to 2D-SRT even with 'standard' RT doses (50 Gy) by a linear accelerator. Using a cobalt source, only a reduced dose (30 Gy) can be delivered by 2D-CRT. However, it should be noted that these types of accelerated-hypo-fractionated treatments (30 Gy, 3 Gy/fraction) were successfully used not only for palliation (12) but also in curative (13) and neoadjuvant (14) treatments.

As expected, the results of 2D-CRT were slightly lower compared to 3D-CRT. Probably, this difference was partially due to the additional margin to account for possible inaccuracies in the calculation of the distances between point $\mathrm{A}$ and point B (transfer error). In this analysis, to this margin was arbitrarily assigned a value of $1 \mathrm{~cm}$. Prospective assessments 
on the extent of the 'transfer error' could allow an optimization of this margin.

It should be emphasized that using 2D-CRT technique is of utter most importance that the patient is properly aligned. This allows precise measurement of the distance between point $\mathrm{A}$ and $\mathrm{B}$ in the lateral direction.

Unfortunately, to achieve a wide spread of 3D-CRT technology in all RT centres in the world will require several years given the economic costs and logistic problems. In the meantime, the use of 2D-CRT technique may be useful to improve the quality of treatments in various anatomical sites even for centers in low and middle-income countries. Therefore, it could be useful to assess this method in RT treatment of other tumors. Furthermore, testing and clinical validation of the feasibility and reproducibility of this technique in the setting of developing countries is highly encouraged.

For these reasons, further studies have been planned in our center to evaluate 2D-CRT in the treatment of prostate cancer and in palliative treatments of advanced pelvic malignancies.

\section{Acknowledgements}

Not applicable.

\section{Funding}

No funding was received.

\section{Availability of data and materials}

All data generated or analyzed during this study are included in this published article.

\section{Authors' contributions}

MB, SaC, FD, GM, TW, AFMK, MAS and AGM were involved in the study conception and design. SaC, MB, SiC, VP, AA, EF, $\mathrm{RF}$ and $\mathrm{AGM}$ were involved in treatment planning, analysis and interpretation of the data. MB, FD, EF, RF, SaC and AGM drafted the article. TW, AFMK, MAS and AGM performed critical revision of the article for important intellectual content.

\section{Ethics approval and consent to participate}

Patients written informed consent for the use of their data and CT images to perform this analysis was sought prior. The institutional ethical committee board approved the study.

\section{Patient consent for publication}

Patients written informed consent for the use of their data and $\mathrm{CT}$ images to perform this analysis was sought prior.

\section{Competing interests}

The authors declare that they have no competing interests.

\section{References}

1. American College of Radiology: ACR practice parameter for $3 \mathrm{D}$ external beam radiation planning and conformal therapy, 2016; Available at: https://www.acr. org/-/media/ACR/Files/Practice-Parameters/3DConformal.pdf. Accessed March 1, 2018.

2. Zubizarreta EH, Fidarova E, Healy B and Rosenblatt E: Need for radiotherapy in low and middle-income countries-the silent crisis continues. Clin Oncol (R Coll Radiol) 27: 107-114, 2015.

3. Page BR, Hudson AD, Brown DW, Shulman AC, Abdel-Wahab M, Fisher BJ and Patel S: Cobalt, linac, or other: What is the best solution for radiation therapy in developing countries? Int $\mathrm{J}$ Radiat Oncol Biol Phys 89: 476-480, 2014.

4. National Comprehensive Cancer Network: NCCN clinical practice guidelines in oncology: Pancreatic adenocarcinoma. Version 3, 2017. Available at: http://www.nccn.org/professionals/ physician_gls/f_guidelines.asp. Accessed March 1, 2018.

5. Buwenge M, Marinelli A, Deodato F, Macchia G, Wondemagegnhu T, Salah T, Cammelli S, Kamal Uddin AFM, Sumon MA, Donati CM, et al: Definition of fields margins for palliative radiotherapy of pancreatic carcinoma. Mol Clin Oncol 8: 715-718, 2018. https://doi.org/10.3892/mco.2018.1605

6. Morgan-Fletcher SL: Prescribing, recording and reporting photon beam therapy (Supplement to ICRU Report 50), ICRU Report 62. ICRU, pp. ix+ 52, 1999 (ICRU Bethesda, MD) \$65.00 ISBN 0-913394-61-0. British Journal of Radiology 74: 294-294, 2001

7. Bentzen SM, Constine LS, Deasy JO, Eisbruch A, Jackson A, Marks LB, Ten Haken RK and Yorke ED: Quantitative Analyses of Normal Tissue Effects in the Clinic (QUANTEC): An introduction to the scientific issues. Int J Radiat Oncol Biol Phys 76 (3 Suppl): S3-S9, 2010.

8. Cheng CW, Chin LM and Kijewski PK: A coordinate transfer of anatomical information from CT to treatment simulation. Int $\mathrm{J}$ Radiat Oncol Biol Phys 13: 1559-1569, 1987.

9. Flickinger JC and Deutsch M: Manual reconstruction of tumor volumes from CT scans for radiotherapy planning. Radiother Oncol 14: 151-158, 1989.

10. Rutten EH, Abma W and van Erning L: Digiplot: A PC programme for drawing tumor volumes for radiation therapy treatment planning using computer tomography images. Radiother Oncol 24: $117-119,1992$.

11. Morganti AG, Marinelli A, Buwenge M, Macchia G, Deodato F, Massaccesi M, Kigula-Mugambe J, Wondemagegnhu T, Dawotola D, Caravatta L, et al: Palliative two-dimensional radiotherapy of pancreatic carcinoma: A feasibility study. Tumori 99: 488-492, 2013.

12. Morganti AG, Trodella L, Valentini V, Barbi S, Macchia G, Mantini G, Turriziani A and Cellini N: Pain relief with short term irradiation in locally advanced carcinoma of the pancreas. J Palliat Care 19: 258-262, 2003.

13. Crane CH, Abbruzzese JL, Evans DB, Wolff RA, Ballo MT, Delclos M, Milas L, Mason K, Charnsangavej C, Pisters PW, et al: Is the therapeutic index better with gemcitabine-based chemoradiation than with 5-fluorouracil-based chemoradiation in locally advanced pancreatic cancer? Int J Radiat Oncol Biol Phys 52: 1293-1302, 2002

14. Pisters PW, Wolff RA, Janjan NA, Cleary KR, Charnsangavej C, Crane CN, Lenzi R, Vauthey JN, Lee JE, Abbruzzese JL and Evans DB: Preoperative paclitaxel and concurrent rapid-fractionation radiation for resectable pancreatic adenocarcinoma: Toxicities, histologic response rates, and event-free outcome. J Clin Oncol 20: 2537-2544, 2002.

This work is licensed under a Creative Commons Attribution-NonCommercial-NoDerivatives 4.0 International (CC BY-NC-ND 4.0) License. 